Check for updates

Cite this: RSC Adv., 2019, 9, 9313

Received 17th December 2018 Accepted 25th February 2019

DOI: $10.1039 / c 8 r a 10352 f$

rsc.li/rsc-advances

\section{The effect of foam quality, particle concentration and flow rate on nanoparticle-stabilized $\mathrm{CO}_{2}$ mobility control foams}

\begin{abstract}
Chunkai Fu, ${ }^{a}$ Jianjia $\mathrm{Yu}^{\mathrm{b}}$ and Ning Liu (D)*a
$\mathrm{CO}_{2}$ foam is regarded as a promising technology and widely used in the oil and gas industry, not only to improve oil production, but also to mitigate carbon emissions through their capture. This paper describes a series of nanoparticle-stabilized $\mathrm{CO}_{2}$ foam generation and foam flow experiments under reservoir conditions. Stable $\mathrm{CO}_{2}$ foam was generated when $\mathrm{CO}_{2}$ and a nanosilica dispersion flowed through the core sample under 1500 psi and $25{ }^{\circ} \mathrm{C}$. The foam changed from a fine-texture foam to a coarse foam as the foam quality increased from $20 \%$ to $95 \%$. Foam mobility increased slightly with the increasing foam quality from $20 \%$ to $80 \%$ and then rapidly from $80 \%$ to $95 \%$. A stable $\mathrm{CO}_{2}$ foam was generated as the nanosilica concentration increased to $2500 \mathrm{ppm}$. Foam mobility and resistance factor increased with the increasing nanosilica concentration. As the injection flow rate increased to $60 \mathrm{ml} \mathrm{h}^{-1}$, stable and fine-texture $\mathrm{CO}_{2}$ foam was obtained. Foam mobility was observed to remain almost constant as the injection flow rate increased from $60 \mathrm{ml} \mathrm{h}^{-1}$ to $150 \mathrm{ml} \mathrm{h}^{-1}$
\end{abstract}

\section{Introduction}

Carbon dioxide $\left(\mathrm{CO}_{2}\right)$ injection is presently one of the most commonly used approaches in The Enhanced Oil Recovery (EOR) application. $\mathrm{CO}_{2}$ can be used either as an immiscible or a miscible displacing agent based on the reservoir conditions and the composition of crude oils. Injection of $\mathrm{CO}_{2}$ can benefit production by mobilizing more oil trapped in the pores of the reservoir rock. However, the lower viscosity of $\mathrm{CO}_{2}$ compared to crude oil induces an unfavorable mobility ratio. In addition, the heterogeneity of the reservoir formation results in an early breakthrough and a poor oil sweep efficiency. ${ }^{1-3}$ The use of surfactant is one way to rectify the drawbacks associated with $\mathrm{CO}_{2}$ flooding. It helps to reduce the viscosity difference between the displacing and displaced fluids by restricting the flow of $\mathrm{CO}_{2}$ through high permeability zones. Today, the major challenges for surfactant EOR are high surfactant retention in porous media and unstable foam properties under hightemperature reservoir conditions. ${ }^{\mathbf{4 - 6}}$

Recently, a new generation of $\mathrm{CO}_{2}$ foam using nanotechnology to create lasting foams has been studied, and this new technology has been attracting more and more attention due to the long-term stability of foams under harsh reservoir conditions. Dickson et al. first reported generating $\mathrm{CO}_{2}$ foam with nanosilica particles. ${ }^{7}$ Nanosilica particles were

${ }^{a}$ Department of Petroleum Engineering, University of Louisiana at Lafayette, Lafayette, LA, USA 70503. E-mail: ning.liu@louisiana.edu

${ }^{b}$ Petroleum Recovery Research Center, New Mexico Institute of Mining and Technology, 801 Leroy Place, Socorro, NM, USA 87801 dispersed in water and then sheared through an orifice with supercritical $\mathrm{CO}_{2} \cdot \mathrm{CO}_{2}$ foam was generated and observed through a view cell. They observed that foam stability increased with the increasing particle concentration, $\mathrm{CO}_{2}$ density, and shear rate. Later, Espinoza et al. proposed the generation of nanoparticle-stabilized supercritical $\mathrm{CO}_{2}$ foams $\left(\mathrm{CO}_{2}\right.$ in water foam) for potential mobility control applications by using commercial surface-modified silica particles. ${ }^{8}$ The foams were generated by co-injecting $\mathrm{CO}_{2}$ and an aqueous dispersion of the nanoparticles through a glass-bead pack. They demonstrated that supercritical $\mathrm{CO}_{2}$ foams could be generated by nanoparticles with a concentration as low as $0.05 \mathrm{wt} \%$. Andrew et al. conducted foam generation experiments focused on nanoparticles with different surface coatings and demonstrated that the larger size of $50 \% \mathrm{SiOH}$ nanoparticles resulted in stronger stable $\mathrm{CO}_{2}$ foams compared to those generated with PEG-coated silica particles. ${ }^{9}$ Singh and Mohanty investigated the process of foam stabilized by in situ surface-activated nanoparticles in bulk and porous media. ${ }^{\mathbf{1 0}}$ Alumina-coated silica nanoparticles were mixed with different concentrations of propyl gallate (PG) and the particle hydrophilic surface was converted to partially hydrophobic by anchoring PG molecular to the particle surface. They observed a strong foaming tendency with surface-modified nanoparticles (SMNPs). The bubble texture of foam stabilized by SMNPs was finer than that with surfactants. In the same time, some researchers studied the process of nanoparticles surface modification with surfactants. ${ }^{\mathbf{1 1 , 1 2}}$ A synergic interaction between surfactant and nanoparticles was observed to generate stable foam. For 
example, Worthen et al. ${ }^{12}$ reported the generation of viscous and stable $\mathrm{CO}_{2}$ foams with fine texture by use of bare silica nanoparticles and zwitter-ionic surfactant, when neither of these species could stabilize foam independently. More recently, nanoparticle-stabilized $\mathrm{CO}_{2}$ foam flow behavior was studied by Prigiobbe et al. ${ }^{13}$ A two-phase flow mechanistic model combining the mass conservation law and the population balance equation was implemented to analyze the $\mathrm{CO}_{2}$ foam transport in porous media. Their results indicated that the two-phase flow model described well the experiments when a strong high-quality foam was generated.

Although some researches were performed on nanoparticlestabilized $\mathrm{CO}_{2}$ foam generation, field tests with high pressure $\mathrm{CO}_{2}$ foam indicated that field application of $\mathrm{CO}_{2}$ foam was a technically viable process for improved oil recovery. ${ }^{\mathbf{1 4}}$ An efficient evaluation of candidate reservoirs for possible $\mathrm{CO}_{2}$ foam application requires a fundamental understanding of information on $\mathrm{CO}_{2}$ foam behavior under various foam test conditions. In our previous studies, the effects of different ions and temperature on nanosilica-stabilized $\mathrm{CO}_{2}$ foam generation were studied. ${ }^{15}$ More $\mathrm{CO}_{2}$ foam was generated as the $\mathrm{NaCl}$ concentration increased from $1.0 \%$ to $10 \%$. Also the foam texture became finer and foam stability improved with the $\mathrm{NaCl}$ concentration increase. In this paper, the effects of foam quality, particle concentration, and flow rate on nanoparticlestabilized $\mathrm{CO}_{2}$ foam generation, foam texture, foam stability, and foam flow behavior in a porous medium were investigated.

\section{Experimental}

\subsection{Materials}

Silica nanoparticles were obtained from Akzo Nobel Pulp and Performance Chemicals Inc. as an aqueous dispersion and diluted with $2.0 \% \mathrm{NaCl}$ to the desired concentration. Particle size and morphology were characterized by dynamic light scattering (DLS) and transmission electron microscopy (TEM). Berea sandstone core samples were purchased from Cleveland Quarries. The core was cut and polished to a diameter of $2.12 \mathrm{in}$. and a length of $8.3 \mathrm{in}$. Then the core was loaded into a core holder with an overburden pressure of 3500 psi. The initial brine permeability and the porosity of the core were measured as $33.0 \mathrm{mD}$ and $17.4 \%$, respectively. The pore volume (PV) of the core was calculated as $100.4 \mathrm{ml}$.

\subsection{Experiment devices}

Fig. 1 shows the experimental apparatus for $\mathrm{CO}_{2}$ foam generation. First, $\mathrm{CO}_{2}$ and nanosilica dispersion were stored in two floating piston accumulators, respectively. Two TEMCO Back Pressure Regulators (BPR) were used to maintain the accumulator under required operating pressure. During the $\mathrm{CO}_{2}$ foam generation, two ISCO syringe pumps (model 260D) were used to inject distilled water into the $\mathrm{CO}_{2}$ /nanosilica dispersion accumulators, forcing nanosilica dispersion and $\mathrm{CO}_{2}$ flow out from the accumulator under operating pressure. The injected high pressure $\mathrm{CO}_{2}$ and nanosilica dispersion were mixed in the core sample, providing the shear energy to drive the nanosilica particles to adsorb into the interface between $\mathrm{CO}_{2}$ and water. A sapphire observation cell was installed behind the core holder to estimate the foam morphology and bubble size. Pressure drop along the core was measured with a Honeywell 3000 differential pressure transducer connected to a Daq56 data acquisition system. After the observation cell, another accumulator was used to collect the $\mathrm{CO}_{2}$ and nanosilica mixture. The third BPR was installed after the accumulator to control the operation pressure in the core sample and observation cell. The entire apparatus, except for the syringe pumps, was placed in an

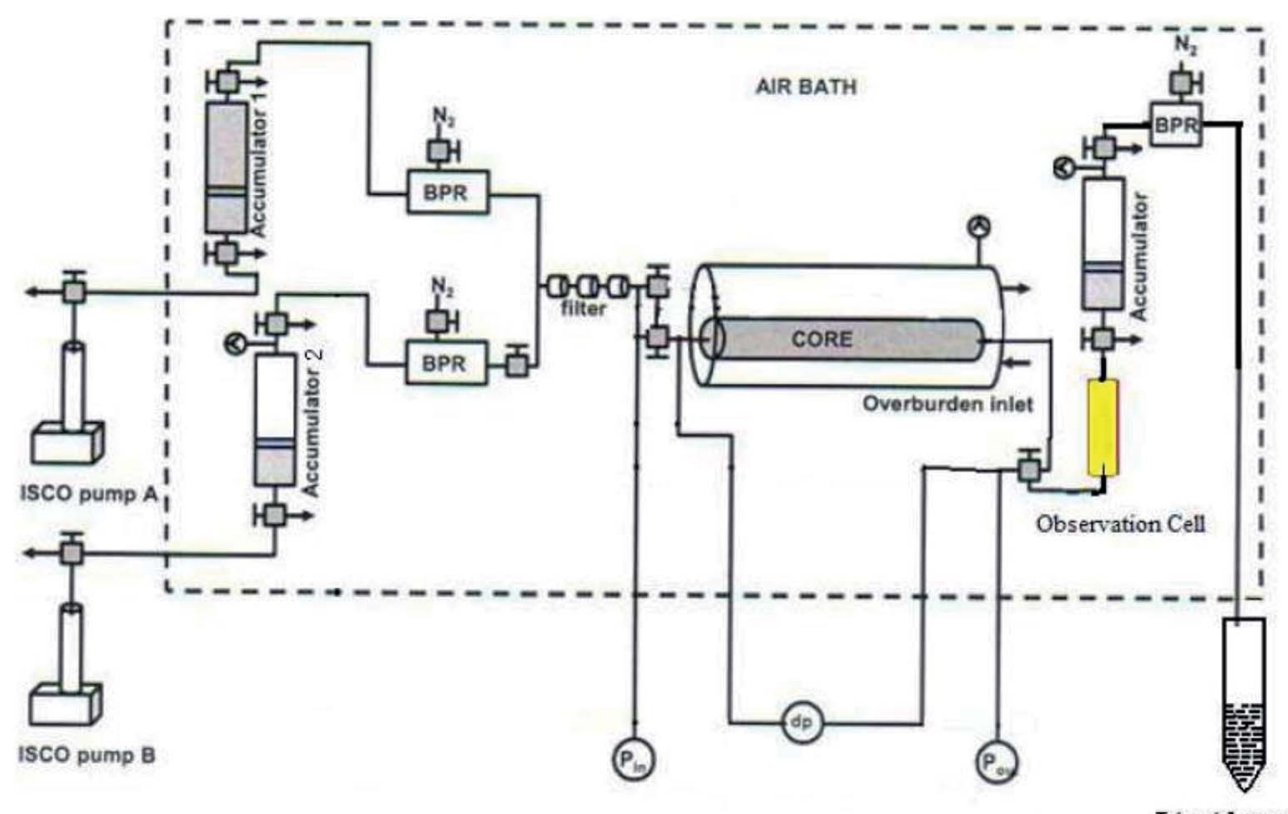

Liquid trap

Fig. 1 Sketch of the $\mathrm{CO}_{2}$ foam generation. 
air bath to maintain a constant temperature throughout the experiment.

All the core-flooding tests were conducted at $25{ }^{\circ} \mathrm{C}$ and 1500 psi. To evaluate the effect of nanosilica on $\mathrm{CO}_{2}$ foam generation and mobility control, baseline experiments were first performed by simultaneously injecting $\mathrm{CO}_{2}$ and brine into the core at different volumetric injection ratios without nanosilica particles. Each baseline experiment lasted until a steady-state pressure drop was achieved.

\subsection{Characterization}

2.3.1 Foam mobility. The foam mobility in this study is defined as the total mobility of $\mathrm{CO}_{2} /$ nanosilica dispersion. The mobility can be evaluated by eqn (1):

$$
\lambda=\frac{q L}{A \Delta P}
$$

where $q\left(\mathrm{ml} \mathrm{s}^{-1}\right)$ is the flow rate; $A\left(\mathrm{~cm}^{2}\right)$ and $L(\mathrm{~cm})$ are the crossarea and length of the core, respectively; $\Delta P$ (atm) is the pressure drop along the core; $\lambda$ is the mobility with the unit of $\mathrm{D}^{-1}$.

2.3.2 Foam resistance factor. The foam resistance factor here is defined as the ratio of the total mobility of $\mathrm{CO}_{2} /$ brine divided by the foam mobility (total mobility of $\mathrm{CO}_{2} /$ nanosilica dispersion) at the same flow rate and phase ratio. In this study, the same sandstone core was used for all tests. The calculation of the foam resistance factor is as follows:

$$
\gamma=\frac{\Delta P_{\mathrm{CO}_{2}-\mathrm{NPs}}}{\Delta P_{\mathrm{CO}_{2}-\text { brine }}}
$$

where $\Delta P_{\mathrm{CO}_{2}-\mathrm{NPs}}$ is the pressure drop across the core with $\mathrm{CO}_{2} /$ nanoparticle dispersion injection and $\Delta P_{\mathrm{CO}_{2} \text {-brine }}$ is the pressure drop during baseline experiments with brine and $\mathrm{CO}_{2}$ injection.

\section{Results and discussions}

\section{1 $\mathrm{CO}_{2}$ foam generation in Berea sandstone core}

The diluted nanosilica dispersion (5000 ppm) had an average particle size around $17 \mathrm{~nm}$ as measured by DLS and TEM. Fig. 2 shows the $\mathrm{CO}_{2}$ foam images from the observation cell in the presence and absence of nanosilica particles $\left(\mathrm{CO}_{2}:\right.$ brine $\left.=3: 2\right)$ and the pressure drops along the core. Due to the low viscosity of $\mathrm{CO}_{2}$ and high interfacial tension between $\mathrm{CO}_{2}$ and brine, no stable foam lamella was formed in the absence of nanoparticles. The generated $\mathrm{CO}_{2}$ bubbles were prone to collapse and merge into a $\mathrm{CO}_{2}$ slug (on the top of Fig. 2a). However, a large volume of $\mathrm{CO}_{2}$ foams with a small bubble size was formed as the $\mathrm{CO}_{2}$ and nanosilica dispersion flowed through the core. This suggests that when nanoparticles were introduced to the $\mathrm{CO}_{2} /$ brine system, they were adsorbed at the interfaces between $\mathrm{CO}_{2}$ and brine, stabilizing the foam by mitigating processes such as coalescence and Ostwald ripening. ${ }^{13}$

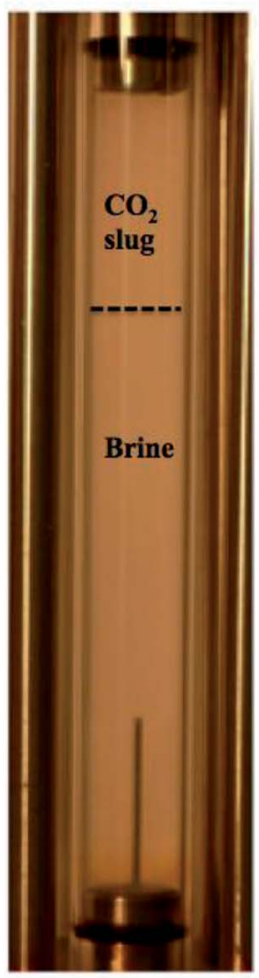

(a)

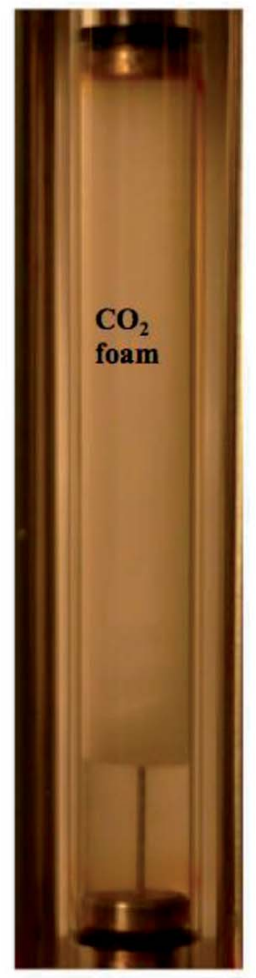

(b)

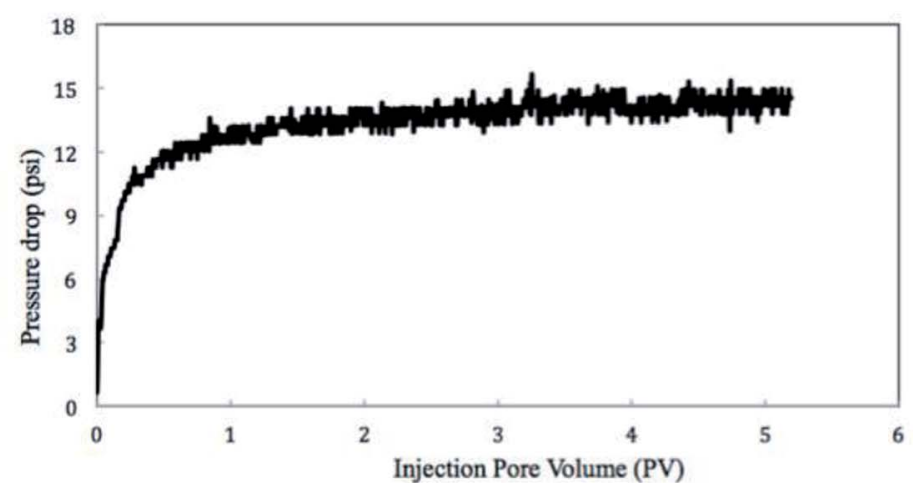

(c)

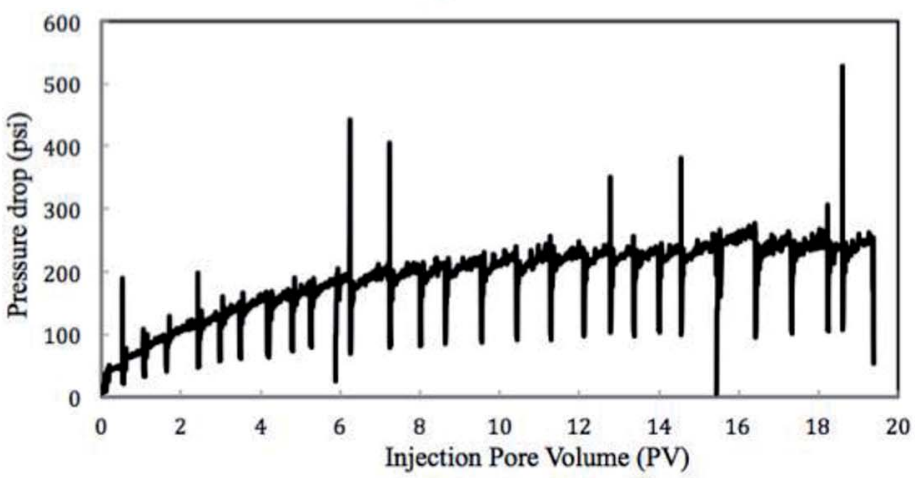

(d)

Fig. 2 Images of $\mathrm{CO}_{2}$ foam with brine and $\mathrm{CO}_{2}$ (a); nanosilica and $\mathrm{CO}_{2}$ (b) and pressure drop along the core in $\mathrm{CO}_{2} / \mathrm{brine}$ core flood (c); in $\mathrm{CO}_{2} /$

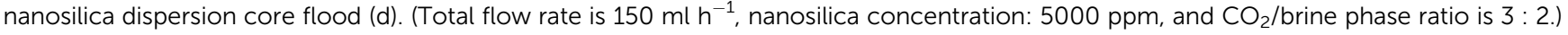




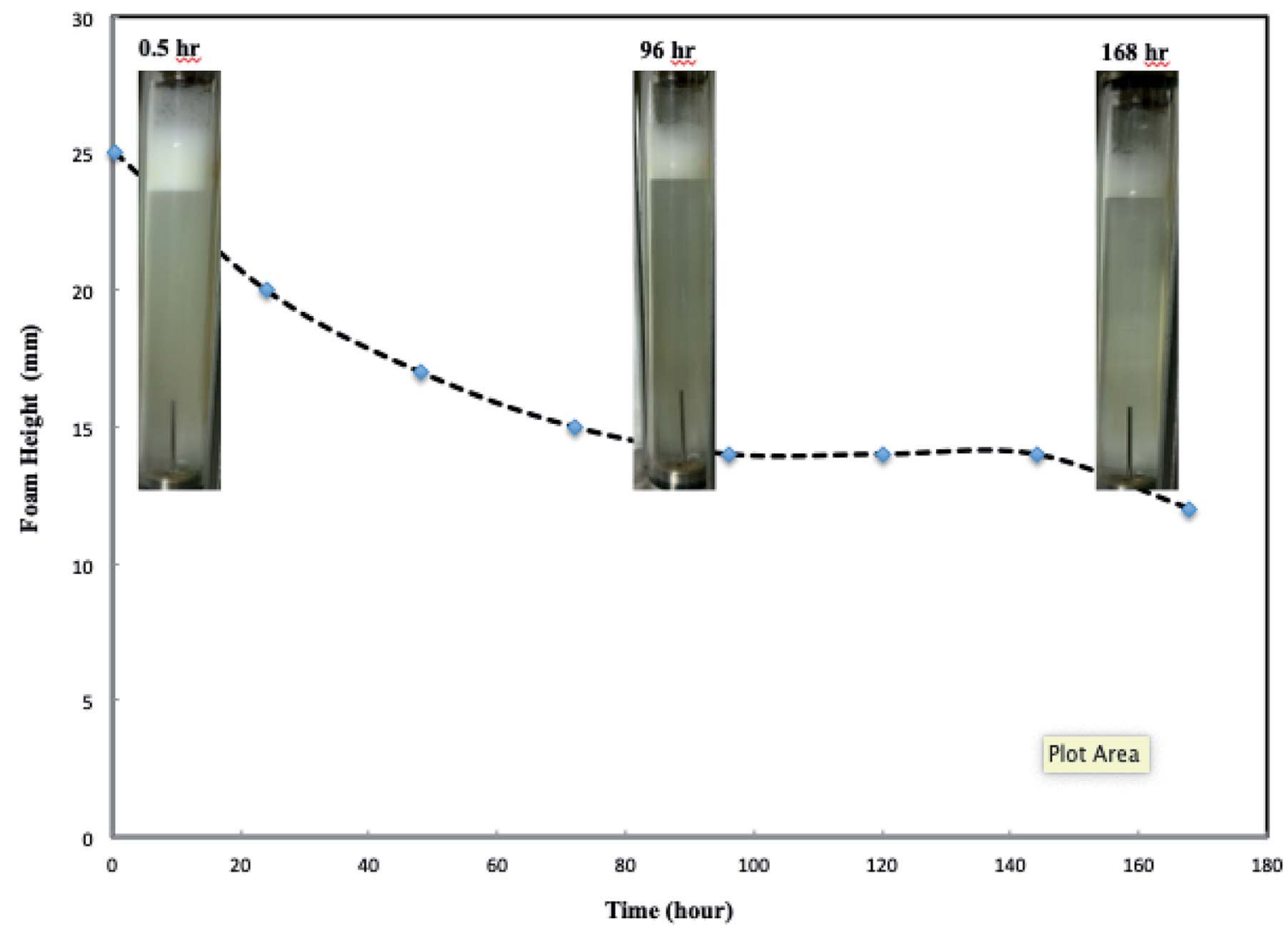

Fig. $3 \mathrm{CO}_{2}$ foam images height change with standing time. (Total flow rate is $150 \mathrm{ml} \mathrm{h}^{-1}$, nanosilica concentration: $5000 \mathrm{ppm}$, and $\mathrm{CO}_{2} / \mathrm{brine}$ phase ratio is $3: 2$.)

Fig. 2 also displays the pressure drops along the core in $\mathrm{CO}_{2} /$ brine and $\mathrm{CO}_{2} /$ nanosilica dispersion core-flooding tests. In the $\mathrm{CO}_{2} /$ nanosilica dispersion core flood test, nanosilica dispersion was diluted with $2.0 \% \mathrm{NaCl}$ solution to the particle concentration of $5000 \mathrm{ppm}$. The results of the pressure drop along the core indicated that, as nanosilica was introduced, the pressure

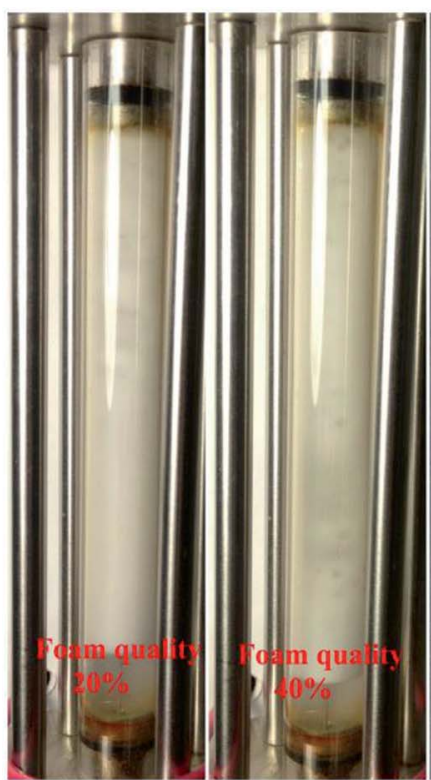

(a) (b)

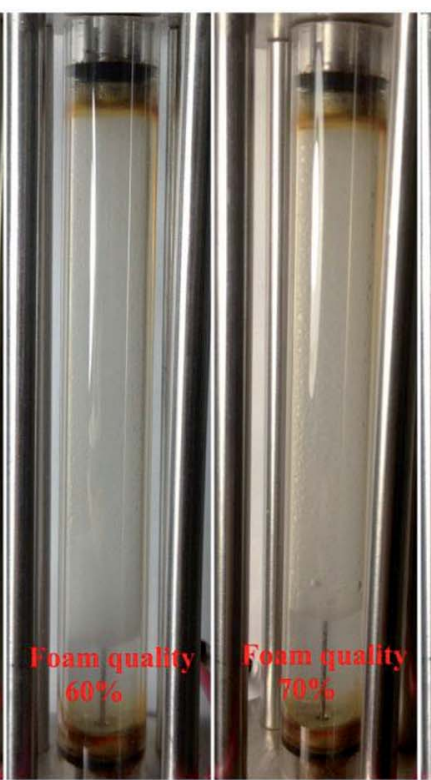

(c) (d)

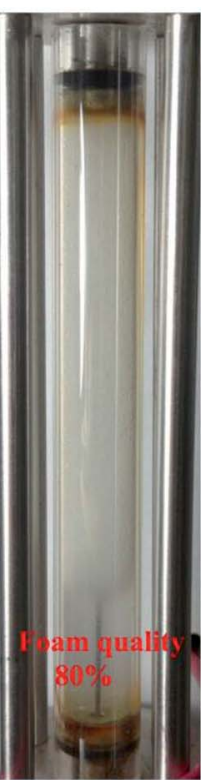

(e)

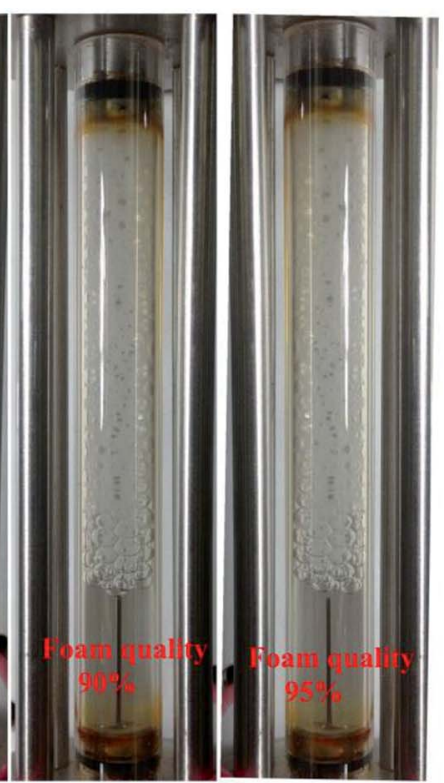

(f)

(g)

Fig. 4 Images of foam generation at different foam quality. (Total flow rate is $150 \mathrm{ml} \mathrm{h}^{-1}$; nanosilica concentration: 5000 ppm; images captured as the foam flowed in the observation cell.) 
drop was much higher than that of in absence of nanosilica particles. The higher pressure drop in the presence of nanosilica implied that $\mathrm{CO}_{2}$ foam was generated in the core, resulting in a more "viscous" $\mathrm{CO}_{2}$ fluid. Here, it is necessary to emphasize that the core was flooded with brine after the test, and the core permeability was observed to be almost the same before and after the test, indicating no particle plugging during the test. On the other hand, Fig. $2 \mathrm{c}$ and $\mathrm{d}$ also show that much more injection volumes were required to reach the steady state in the $\mathrm{CO}_{2}$ /nanosilica dispersion core flood test. For example, it took 8-10 PVs of $\mathrm{CO}_{2} /$ nanosilica dispersion to reached the steady state in $\mathrm{CO}_{2} /$ nanosilica dispersion core flood test, while it reached the pressure equilibrium as $1.5 \mathrm{PVs}$ of $\mathrm{CO}_{2} /$ brine were injected in $\mathrm{CO}_{2}$ /brine core flood test. The requirement of high PV injection to reach steady state has also been observed by other researchers and currently is not well understood. ${ }^{16,17}$ The experiments of Ettinger ${ }^{\mathbf{1 7}}$ suggested that the slow increases in pressure were caused by the propagation of a capillary end effect from the back of the core to the front of the core.

Further investigations of the foam stability is shown in Fig. 3, which displays the height of $\mathrm{CO}_{2}$ foam at different times after core-flooding. The inserted images in Fig. 3 show the foam pictures being observed in the observation cell in Fig. 1 with different standing times. The generated $\mathrm{CO}_{2}$ foam, when left at room temperature and 1500 psi, displayed very good stability. Less than one-third of the foams collapsed after standing at room temperature for five days. The half life-time, here is defined the time elapsed when the foam reaches its half of its initial height, was measured around 168 hours. Similarly, Martinez et al. also observed nine months lifetime for nanosilica-stabilized $\mathrm{N}_{2}$ foam. ${ }^{18}$ Worthen et al. ${ }^{12}$ and Binks et al. ${ }^{19}$ reported long-term stable $\mathrm{CO}_{2}$ /air foams generated by nanoparticles.

The long-term stability of nanoparticle-stabilized $\mathrm{CO}_{2}$ foam is attributed to the high adsorption energy of nanosilica particles at the $\mathrm{CO}_{2}$ /brine interface. Horozov reported that particles in a foam existed at the interface in three ways: a monolayer bridge, a bilayer, and a gel inside the liquid lamellae. Binks proposed to estimate the adsorption energy of nanoparticles at nonaqueous/aqueous interface $\operatorname{as}^{\mathbf{2 0}} \Delta G_{\mathrm{ad}}=\pi \alpha^{2} \gamma_{\text {ow }}(1-$ $|\cos \theta|)^{2}$, where $\alpha$ is the particle radius; $\gamma_{\text {ow }}$ is the interfacial tension, and $\theta$ is the contact angle through the aqueous phase. An estimation of the adsorption energy in this study with $\gamma_{\mathrm{CO}_{2}}$ I brine $=25.15 \mathrm{~m} \mathrm{~m}^{-1},{ }^{21} \theta=75^{\circ}$ is $763 k_{\mathrm{B}} T$, which is much larger than the adsorption energy for a typical surfactant molecule at an oil-water interface (which is of the order of several $k_{\mathrm{B}} T$ ). ${ }^{8}$ This high adsorption energy favors irreversible adsorption of the nanoparticles to the $\mathrm{CO}_{2}$ /brine interface and to the formation of solid-like surface layers. Together with the resistance of the interfaces to collapse, this prevents the $\mathrm{CO}_{2}$ bubbles from coarsening and coalescence, ${ }^{22}$ resulting in highly stable $\mathrm{CO}_{2}$ foams.

\section{2 $\mathrm{CO}_{2}$ foam generation with different phase ratios}

It has been reported that the foam quality $\left(\operatorname{vol}_{\mathrm{CO}_{2}}: \operatorname{vol}_{\left(\mathrm{CO}_{2}+\text { brine }\right)}\right)$ is one of the controversial parameters affecting foam flow behavior. ${ }^{22,23}$ Core-flooding tests of different $\mathrm{CO}_{2} /$ nanosilica dispersion phase ratios were conducted to investigate the effects of volumetric phase ratio on $\mathrm{CO}_{2}$ foam behavior such as foam generation and foam mobility. Fig. 4 displays the $\mathrm{CO}_{2}$ foam images at different foam qualities. At low foam quality regime such as Fig. $4 \mathrm{a}$ and b, collisions and interactions between bubbles are infrequent and weak, and the possibility of bubble collapse decreases. ${ }^{24}$ The generated $\mathrm{CO}_{2}$ foams were fine-textured with uniform bubble size. In addition, the low foam quality implied high brine content, which could produce more stable liquid lamellae and supply sufficient nanoparticles around the foam bubbles, resulting in more stable $\mathrm{CO}_{2}$ foams. The results in Fig. 4 indicated that the $\mathrm{CO}_{2}$ foam with a foam quality of $20 \%$ displayed fine-texture structure with excellent foam stability. The height of the foam did not change after standing for four days. At intermediate foam quality regime such as Fig. 4c-e, the generated $\mathrm{CO}_{2}$ foam displayed larger bubble size compared with that of low foam quality. More bubble collisions and interactions might occur and result in slightly more coarse foams. However, the generated $\mathrm{CO}_{2}$ foam still displayed very good stability. The height of the foam remained almost unchanged after 48 hours. The further increase of $\mathrm{CO}_{2}$ phase ratio to a higher foam quality regime

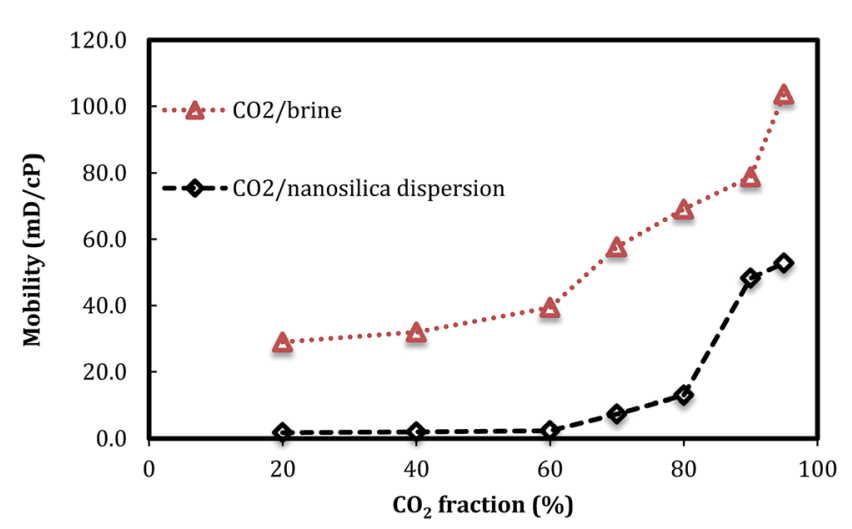

Fig. $5 \mathrm{CO}_{2}$ foam mobility versus foam quality. (Total flow rate is $150 \mathrm{ml} \mathrm{h}^{-1}$, nanosilica concentration: $5000 \mathrm{ppm}$.)

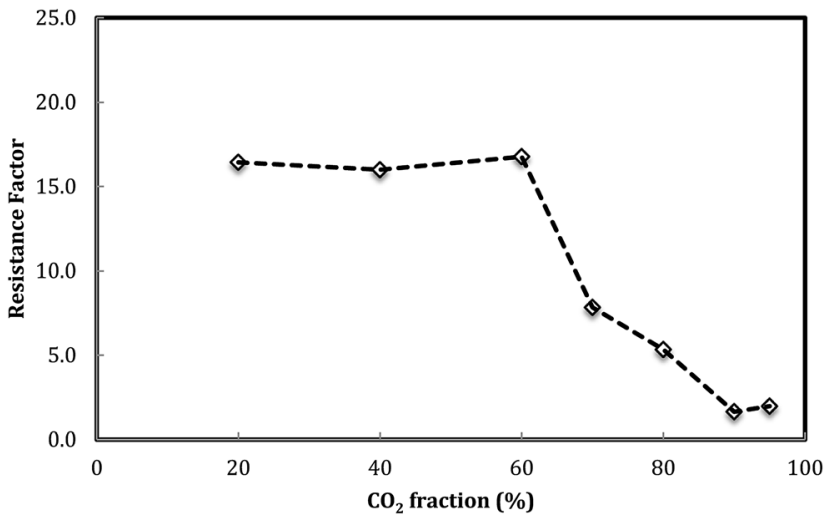

Fig. 6 Foam resistance factor versus foam quality. (Total flow rate is $150 \mathrm{ml} \mathrm{h}{ }^{-1}$, nanosilica concentration: 5000 ppm.) 


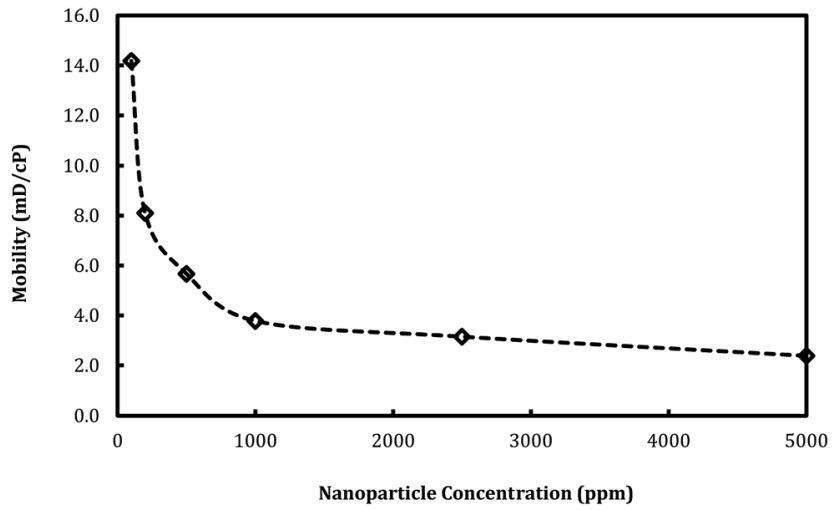

Fig. 7 Foam mobility versus particle concentration. (Total flow rate is $150 \mathrm{ml} \mathrm{h}^{-1}$, and $\mathrm{CO}_{2} /$ brine is $3: 2$.)

resulted in more coarse $\mathrm{CO}_{2}$ foams (Fig. $4 \mathrm{f}$ and g). Foam coarsening and coalescence were enhanced and resulted in the deterioration of foam stability. For example, the lifetime of the $\mathrm{CO}_{2}$ foam was several hours as the foam quality was $95 \%$ (Fig. 4g).

Fig. 5 shows the changes of foam mobility with foam quality. The results clearly indicate that, in the presence of nanosilica particles, the $\mathrm{CO}_{2}$ foam mobilities are lower than those of $\mathrm{CO}_{2}$ / brine with the same phase ratio. The low foam mobility greatly benefits $\mathrm{CO}_{2}$ mobility control in $\mathrm{CO}_{2}$ EOR operation. Fig. 6 also shows that the $\mathrm{CO}_{2}$ foam mobility increased slightly as foam quality increased from $20 \%$ to $80 \%$ and then increased rapidly from $80 \%$ to $95 \%$. The effect of foam quality on foam flow behavior has been widely investigated with surfactant as the $\mathrm{CO}_{2}$ foam stabilizer. For example, Lee and $\mathrm{Heller}^{25}$ reported that $\mathrm{CO}_{2}$ foam mobility increased with the increasing foam quality from $60 \%$ to $90 \%$. De Vries and $\mathrm{Wit}^{26}$ performed a series of tests and concluded that a critical point (breakpoint) for foam mobility existed at an imposed total flow rate; beyond that point, foam mobility increased with foam quality. The results in Fig. 5 indicated that the foam quality of $80 \%$ might be the critical point, beyond which the foam mobility quickly increased. In addition, $\mathrm{CO}_{2}$ foam images in Fig. 4 also indicated that more coarse foams were generated as the foam quality was higher than $80 \%$, which was consistent with the foam mobility change.

Fig. 6 shows the foam resistance factor versus foam quality. The results display that foam resistance factor slightly increases with the increasing foam quality from $20 \%$ to $60 \%$ and then decreases as foam quality further increases. There appeared to be a maximum foam resistance factor obtained at a foam quality of around $60 \%$.

\subsection{Effect of nanosilica concentration on foam mobility}

The effect of nanosilica concentration on foam flow behavior in sandstone was investigated. Tests were conducted at a foam quality of $60 \%$ and a total flow rate of $150 \mathrm{ml} \mathrm{h}^{-1}$ with varying

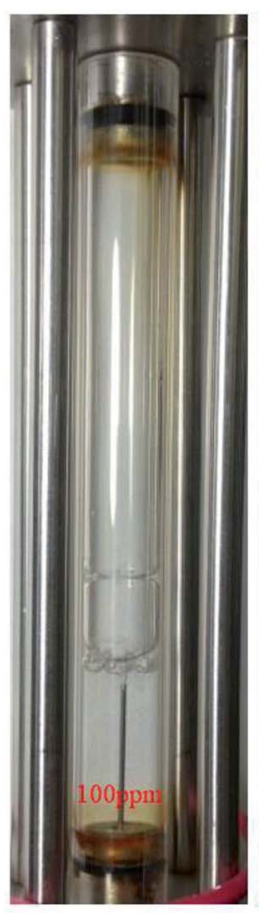

(a) 100ppm

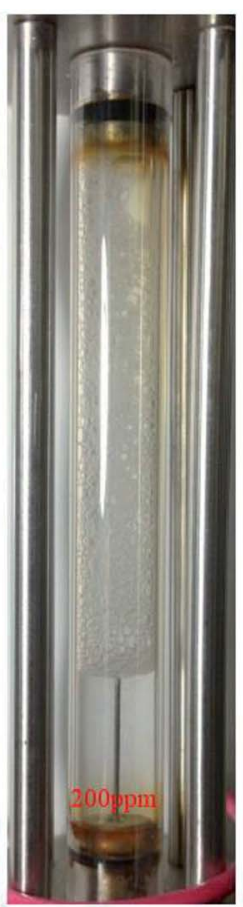

(b) $200 \mathrm{ppm}$

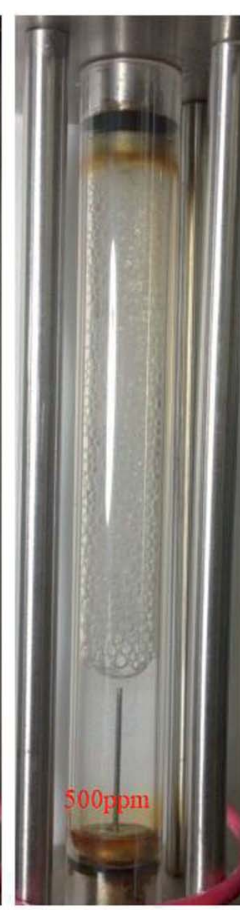

(c) 500ppm
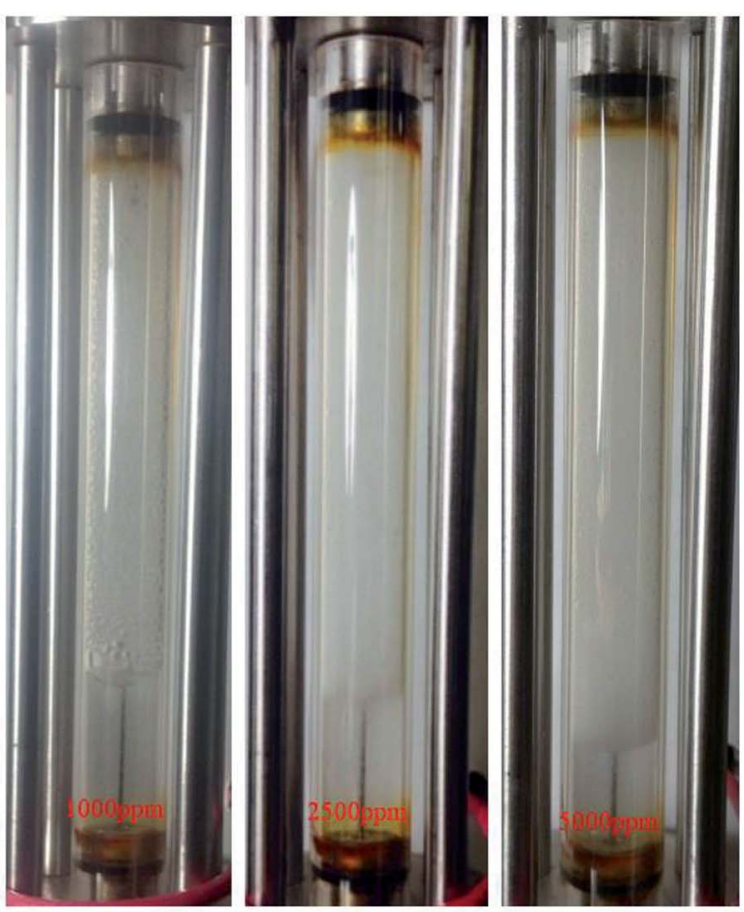

(d) $1000 \mathrm{ppm}$ (e) $2500 \mathrm{ppm}$

Fig. 8 Images of the $\mathrm{CO}_{2}$ foam generation at different nanosilica concentrations. (Total flow rate $=150 \mathrm{ml} \mathrm{h}-1 ; \mathrm{CO}_{2} / \mathrm{brine}=3: 2 ;$ images captured as the foam flowed in the observation cell.) 
particle concentration ranging from $100 \mathrm{ppm}$ to $5000 \mathrm{ppm}$. A plot of foam mobility versus nanosilica concentration is shown in Fig. 7. Foam mobility was reduced as the nanosilica concentration increased. The foam mobility decreased sharply from $14.2 \mathrm{mD} \mathrm{cP}^{-1}$ to $3.78 \mathrm{mD} \mathrm{cP}^{-1}$ as the nanosilica concentration increased from $100 \mathrm{ppm}$ to $1000 \mathrm{ppm}$, then decreased slowly as the particle concentration increased from $2500 \mathrm{ppm}$ to $5000 \mathrm{ppm}$. This could be attributed to the formation of lamellae in the pore spaces between $\mathrm{CO}_{2}$ and brine, ${ }^{27}$ which becomes more stable as the nanosilica concentration increased. Stability of the lamellae improved the foam's resistance to coalescence and allowed more $\mathrm{CO}_{2}$ to flow through the core sample. Foam images in Fig. 8 indicated that the foam height increased with the increasing nanosilica concentration from $100 \mathrm{ppm}$ to $5000 \mathrm{ppm}$, which was consistent with the results of foam mobility. In addition, the foam

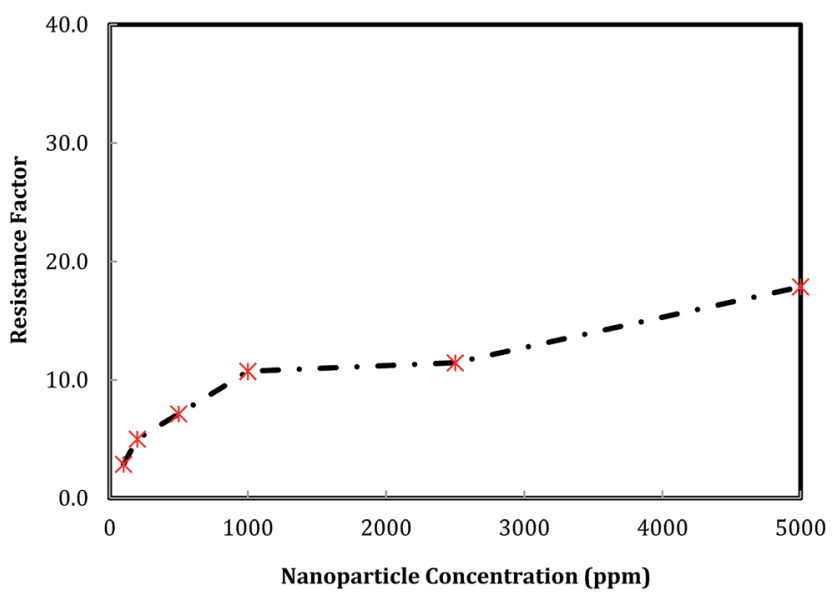

Fig. 9 Foam resistance factor versus particle concentration. (Total flow rate is $150 \mathrm{ml} \mathrm{h}^{-1}$, and $\mathrm{CO}_{2}$ /brine is $3: 2$.) texture was observed to be finer as the nanosilica concentration increased, indicating more stable foam generated at a higher concentration of nanosilica dispersion. The role of particle concentration in foam stability can be rationalized by surface coverage. To generate stable foam, the foam bubbles surface should be sufficiently covered by particles to resist coalescence. Assuming the maximum particle surface concentration $(T)$ is $\Gamma_{\max }=50 \mathrm{mg} \mathrm{m}^{-2}$ and bubble radii are of $25 \mu \mathrm{m}, \mathrm{Rio}^{28}$ estimated that a minimum particle concentration of $0.7 \%$ was required to generate stable foams with the particle size of $10 \mathrm{~nm}$. Our results indicated that stable $\mathrm{CO}_{2}$ foam was generated as the nanosilica concentration was $0.25 \%$, which was close to Rio's estimation. The dependence of the foam resistance factor on particle concentration is plotted in Fig. 9. The resistance factor was 2.9 for a particle concentration as low as $100 \mathrm{ppm}$. As the nanosilica concentration was increased from $100 \mathrm{ppm}$ to $1000 \mathrm{ppm}$, the resistance factor increased to 10.7, and then slowly increased to 16.8 as the nanosilica concentration increased to $5000 \mathrm{ppm}$.

\subsection{Effect of flow rate on foam mobility}

A plot of foam mobility $v s$. flow rate at a particle concentration of $5000 \mathrm{ppm}$ and a foam quality of $60 \%$ is shown in Fig. 10. The total foam mobility was reduced from $9.6 \mathrm{mD} / \mathrm{cp}$ to $2.3 \mathrm{mD} / \mathrm{cp}$ as the flow rate increased from $20 \mathrm{ml} \mathrm{h}^{-1}$ to $60 \mathrm{ml} \mathrm{h}^{-1}$. The significant mobility reduction can be explained by the increasing shear rate from the flow rate increase, which in turn facilitates silica nanoparticle attachment at the water- $\mathrm{CO}_{2}$ interface, resulting in more stable $\mathrm{CO}_{2}$ foam as in Fig. 11. Further increase of the flow rate from $60 \mathrm{ml} \mathrm{h}^{-1}$ to $150 \mathrm{ml} \mathrm{h}^{-1}$ did not result in noticeable mobility change, indicating that stable $\mathrm{CO}_{2}$ foam could be obtained at a flow rate of $60 \mathrm{ml} \mathrm{h}^{-1}$. It should be noted that, in some of studies with $\mathrm{CO}_{2}$ foam, foam mobility increased with flow rate increase or called shear-thinning, ${ }^{23}$ and in other studies, foam mobility decreased with flow

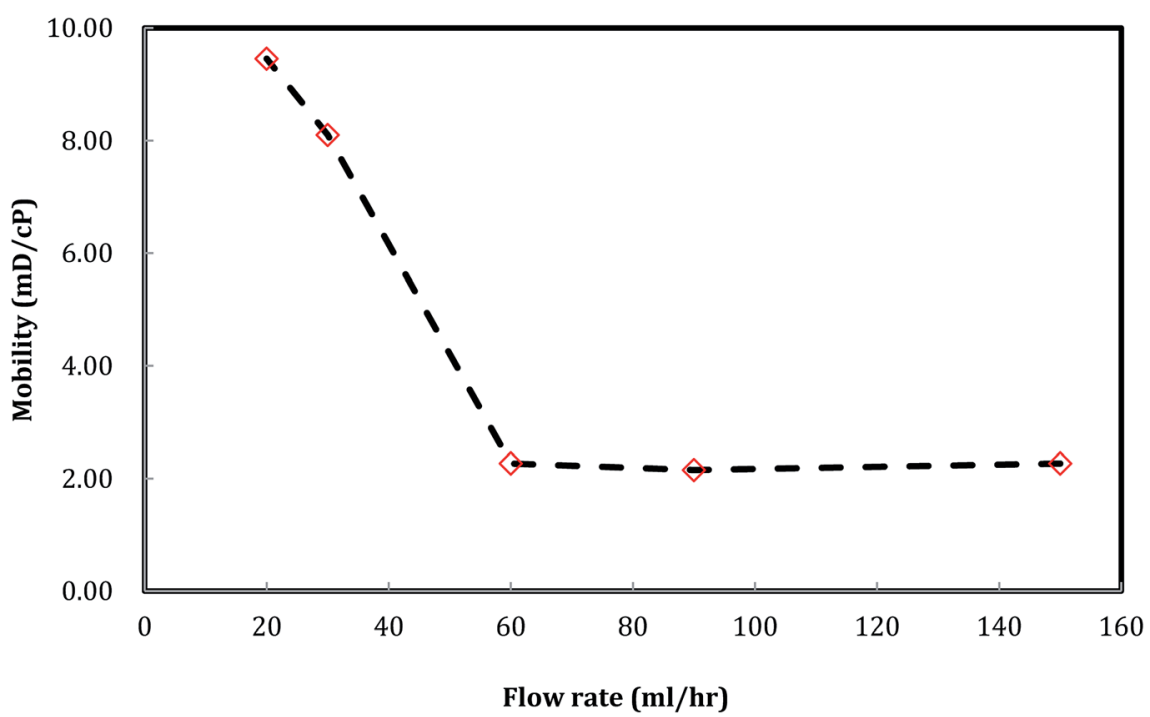

Fig. 10 Foam mobility versus flow rate. (Nanosilica concentration: $5000 \mathrm{ppm}$, and $\mathrm{CO}_{2} /$ brine is 3 : 2.) 


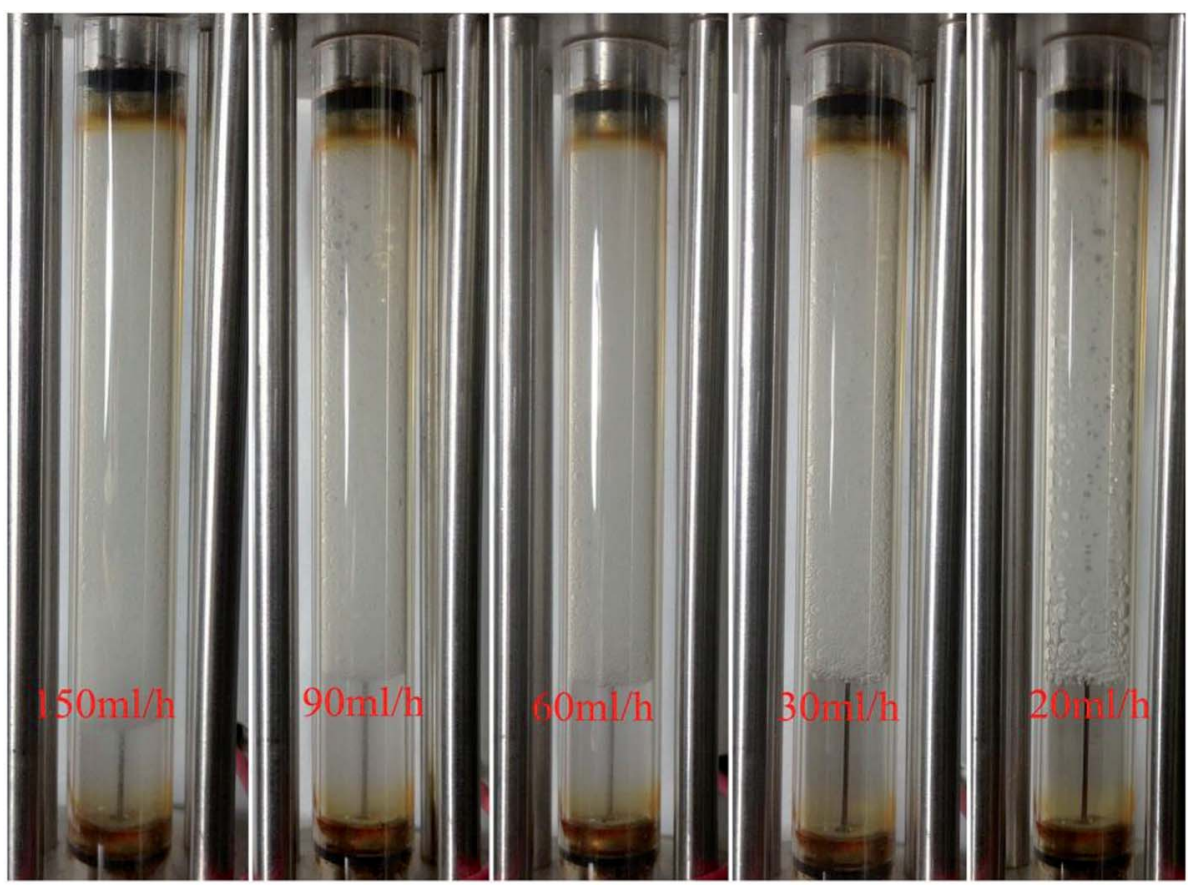

Fig. 11 Images of $\mathrm{CO}_{2}$ foam generated at different flow rates. (Nanosilica concentration: $5000 \mathrm{ppm} ; \mathrm{CO}_{2} / \mathrm{brine}$ is $3: 2$; images captured as the foam flowed in the observation cell.)

rate increase or called shear-thickening. ${ }^{29,30}$ Here we believe that the foam texture and stability need to be considered in understanding foam flow behavior. Fig. 11 shows the images of foam generation at different injection rates with a foam quality of $60 \%$ and a nanosilica concentration of $5000 \mathrm{ppm}$. It shows that finer and more stable $\mathrm{CO}_{2}$ foams were obtained as the flow rate increased from $20 \mathrm{ml} \mathrm{h}^{-1}$ to $60 \mathrm{ml} \mathrm{h}^{-1}$. It is expected that the finer and stable foam can decrease the foam mobility as it flow through a porous medium.
A similar result emerges from the relationship between the foam resistance factor and the flow rate in Fig. 12. The resistance factor slightly increased from 3.2 to 3.3 as the flow rate increased from $20 \mathrm{ml} \mathrm{h}^{-1}$ to $30 \mathrm{ml} \mathrm{h}^{-1}$, and then jumped to 14.3 as the flow rate further increased to $60 \mathrm{ml} \mathrm{h}^{-1}$. Then, the resistance factor slowly increased from 14.3 to 17.9 as the flow rate increased from $60 \mathrm{ml} \mathrm{h}^{-1}$ to $150 \mathrm{ml} \mathrm{h}^{-1}$. It is well-known that foam propagation in porous media is a process of breaking and reforming the lamellae of the foam. The more

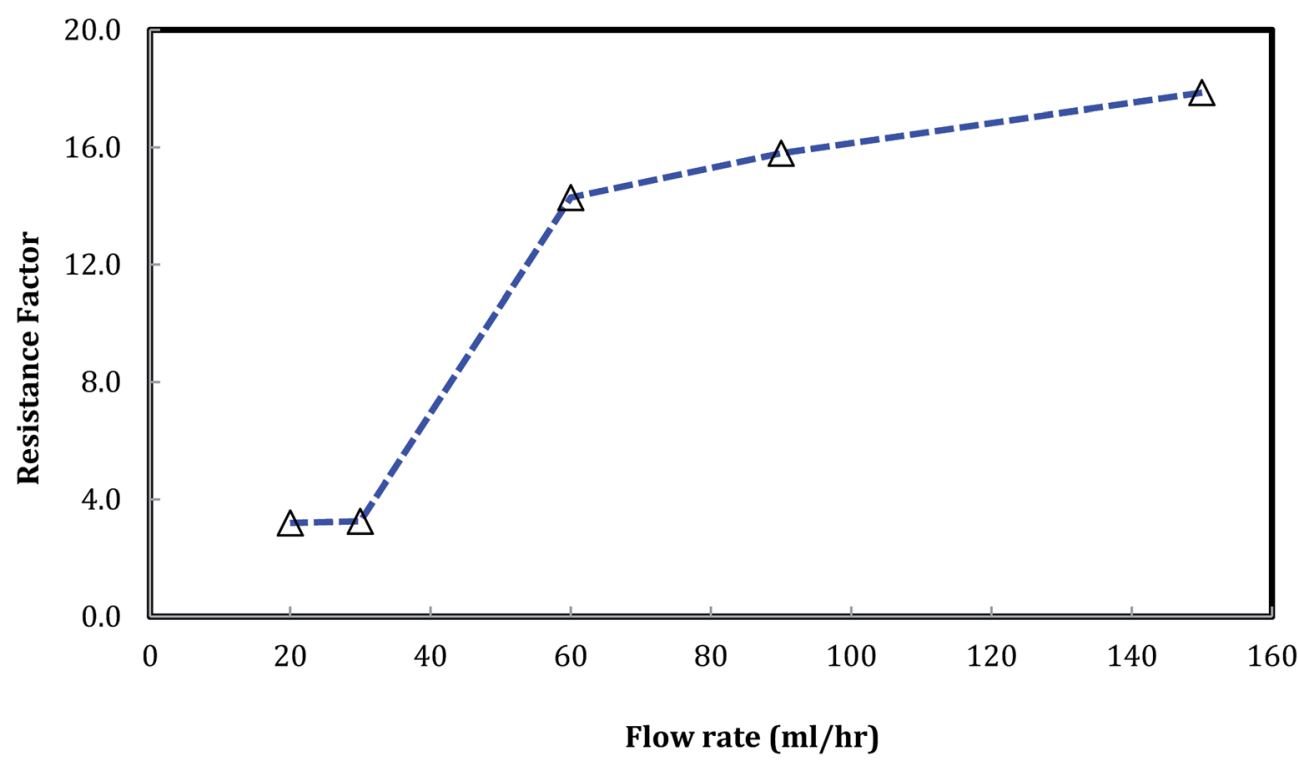

Fig. 12 Foam resistance factor versus flow rate. (Nanosilica concentration: $5000 \mathrm{ppm}$, and $\mathrm{CO}_{2} /$ brine is $3: 2$.) 
stable the lamellae, the higher the resistance factor of the foam. Our results indicate that stable lamellae start to form when the flow rate is around $60 \mathrm{ml} \mathrm{h}^{-1}$.

\section{Conclusions}

(1) A stable $\mathrm{CO}_{2}$ foam was generated when $\mathrm{CO}_{2}$ and nanosilica dispersion flowed through a core sample.

(2) Foam mobility slightly increased with the increasing foam quality from $20 \%$ to $80 \%$ and then rapidly increased as the foam quality increased from $80 \%$ to $95 \%$.

(3) With the increase of nanosilica concentration, foam mobility decreased and the foam resistance factor increased. The threshold concentration required to generate a stable $\mathrm{CO}_{2}$ foam was $2500 \mathrm{ppm}$ under the experimental conditions herein.

(4) Foam mobility decreased with the increasing flow rate from $20 \mathrm{ml} \mathrm{h}^{-1}$ to $60 \mathrm{ml} \mathrm{h}^{-1}$ and then slightly changed as the flow rate increased from $60 \mathrm{ml} \mathrm{h}^{-1}$ to $150 \mathrm{ml} \mathrm{h}^{-1}$.

\section{Conflicts of interest}

There are no conflicts to declare.

\section{Acknowledgements}

We gratefully acknowledge the support of the Department of Energy through the National Energy Technology Laboratory under contract number DE-FE0031575. The authors also thank AkzoNobel Pulp and Performance Chemicals to provide free silica nanoparticle samples.

\section{References}

1 G. G. Bernard and L. W. Holm, Effect of foam on permeability of porous media to gas, SPE J., 1964, 4, 267.

2 L. L. Schramm, Foams: Fundamentals and Applications in the Petroleum Industry, Adv. Chem., 1994, 242, 3.

3 W. R. Rossen, Foams in enhanced oil recovery, Foams: theory, measurements and applications, Marcel Dekker, New York, 1996.

4 G. C. Wang, A Laboratory Study of $\mathrm{CO}_{2}$ Foam Properties and Displacement Mechanism. Paper SPE 12645 presented at the SPE Enhanced Oil Recovery Symposium, Tulsa, Oklahoma, USA, April 15-18, 1984.

5 T. C. Ransohoff and C. J. Radke, Mechanisms of foam generation in glass-bead packs, SPE Reservoir Eng., 1988, 3, 573.

6 J. S. Kim, Y. Dong and W. R. Rossen, Stead-state flow behavior of $\mathrm{CO}_{2}$ foam. Paper SPE 89351 presented at the SPE/DOE Symposium on Improved Oil Recovery, Tulsa, Oklahoma, USA, April 17-21, 2004.

7 J. L. Dickson, B. Binks and P. Johnston, Stabilization of carbon dioxide-in-water emulsions with silica nanoparticles, Langmuir, 2004, 20, 7976.

8 D. A. Espinoza, F. M. Caldelas, K. P. Johnston, S. L. Bryant and C. Huh, Nanoparticle-stabilized supercritical $\mathrm{CO}_{2}$ foams for potential mobility control applications. Paper SPE 129925 presented at the SPE Improved Oil Recovery Symposium, Tulsa, Oklahoma, USA, April 24-28, 2010.

9 J. W. Andrew, G. B. Hitesh, S. L. Bryant, C. Huh and K. P. Johnston, Nanoparticle stabilized carbon dioxide in water foams for enhanced oil recovery. Paper SPE 154285 presented at the SPE Symposium on Improved Oil Recovery, Tulsa, Oklahoma, USA, April 14-18, 2012.

10 R. Singh and K. Mohanty, Foams stabilized by in situ surface-activated nanoparticles in bulk and porous media, SPE J., 2016, 21, 121.

11 H. Farhadi, S. Riahi, S. Ayatollahi and H. Ahmadi, Experimental study of nanoparticle-surfactant-stabilized $\mathrm{CO}_{2}$ foam: Stability and mobility control, Chem. Eng. Res. Des., 2016, 111, 449.

12 A. Worthen, S. L. Bryant, C. Huh and K. Johnston, Carbon dioxide-in-water foams stabilized with nanoparticles and surfactant acting in synergy, AIChE J., 2013, 59, 3490.

13 V. Prigiobbe, A. J. Worthen, K. P. Johnston, C. Huh and S. L. Bryant, Transport of nanoparticle-stabilized $\mathrm{CO}_{2}$ foam in porous media, Transp. Porous Media, 2016, 111, 265.

14 M. L. Hoefner and E. M. Evans, $\mathrm{CO}_{2}$ foam: Results from four developmental field trials, SPE Reservoir Eng., 1995, 10, 273.

15 J. San, S. Wang, J. Yu, R. Lee and N. Liu, Nanaoparticle stabilized $\mathrm{CO}_{2}$ foam: Effect of different ions and temperature, SPE J., 2017, 22, 1416.

16 A. S. Aronson, V. Bergeron, M. E. Fagan and C. J. Radke, The influence of disjoining pressure on foam stability and flow in porous media, Colloids Surf., A, 1994, 83, 109.

17 R. A. Ettinger and C. J. Radke, Influence of texture on steady foam flow in Berea sandstone, SPE Reservoir Eng., 1992, 7, 83.

18 A. C. Martinez, E. Rio, G. Delon, A. Saint-Jalmes, D. Langevin and B. P. Binks, On the origin of the remarkable stability of aqueous foams stabilised by nanoparticles: link with microscopic surface properties, Soft Matter, 2008, 4, 1531.

19 B. P. Binks and T. S. Horozov, Aqueous foams stabilized solely by silica nanoparticles, Angew. Chem., Int. Ed., 2005, 44, 3722 .

20 B. P. Binks, Particles as surfactants-similarities and differences, Curr. Opin. Colloid Interface Sci., 2002, 7, 21.

21 E. Rio, W. Drenckhan, A. Salonen and D. Langevin, Unusually stable liquid foams, Adv. Colloid Interface Sci., 2014, 205, 74.

$22 \mathrm{H}$. Yaghoobi, Laboratory investigation of parameters affecting $\mathrm{CO}_{2}$-foam mobility in sandstone at reservoir conditions. paper SPE 29168 presented at the SPE Eastern Regional Meeting, Charleston, West Virginia, USA, November 8-10, 1994.

23 S. H. Chang and R. B. Grigg, Effects of foam quality and flow rate on $\mathrm{CO}_{2}$-foam behavior at reservoir temperature and pressure, SPE Reservoir Eval. Eng., 1999, 2, 248.

24 S. A. Faroughi, A. J. J. Pruvot and J. McAndrew, The rheological behavior of energized fluids and foams with 
application to hydraulic fracturing: Review, J. Pet. Sci. Eng., 2018, 163, 243.

$25 \mathrm{H}$. O. Lee and J. P. Heller, Laboratory measurements of $\mathrm{CO}_{2}{ }^{-}$ foam mobility, SPE Reservoir Eng., 1990, 5, 193.

26 A. S. De Vries and K. Wit, Rheology of gas/water foam in the quality range relevant to steam foam, SPE Reservoir Eng., 1990, 5, 185.

27 P. A. Gauglitz, F. Friedmann, S. I. Kam and W. R. Rossen, Foam generation in homogeneous porous media, Chem. Eng. Sci., 2002, 57, 4037.
28 E. Rio, W. Drenckhan, A. Salonen and D. Langevin, Unusually stable liquid foams, Adv. Colloid Interface Sci., 2014, 205, 74.

29 T. W. Patzek and M. T. Koinis, Kern river steam-foams pilots, J. Pet. Technol., 1990, 42, 496.

$30 \mathrm{~S}$. H. Yang and R. L. Reed, Mobility control using $\mathrm{CO}_{2}$ forms. Paper SPE 19689 presented at the 54th Annual Technical Conference and Exhibition, San Antonio, Texas, USA, October 8-11, 1989. 